\title{
Evaluation of the Radial Distribution of Gadolinium Isotopes in Nuclear Fuel Pins by Secondary Ion Mass Spectrometry (SIMS)
}

\author{
By hans-Urs Zwicky, Ernst T. Aerne, Gerhard Bart, Ferdinand Petrik and Hugo A. Thomi, Paul- \\ Scherrer-Institute (PSI) (formerly EIR), CH-5303 Wuerenlingen, Switzerland
}

Dedicated to Prof. Hans Rudolf von Gunten on the occasion of his $60^{\text {th }}$ birthday

(Received July 4, 1988; revised August 30, 1988)

Secondary ion mass spectrometry/Isotopic distribution/Nuclear fuel/Irradiated/Gadolinium

\begin{abstract}
Secondary Ion Mass Spectrometry (SIMS) is a suitable technique to evaluate the relative isotopic $\mathrm{Gd}$ distribution across fuel pellets. It is faster and provides greater lateral resolu tion than microdrilling techniques. Measurements on polished fuel cross sections with $\mathrm{Gd}_{2} \mathrm{O}_{3}$ contents of 3 and $7 \mathrm{wt} \%$, an initial ${ }^{235} \mathrm{U}$ enrichment of about $3.5 \%$ and burnup values between 2 and $6 \mathrm{GWd} / \mathrm{tM}$ were performed. In spite of cracked and porous surfaces, repeated measurements on the same sample lay within a span of less than $15 \%$ (relative), provided that the residual isotopic abundances were greater than ca. $1 \%$.

The major disadvantage of the SIMS technique is the limitation concerning quantitative analysis. In this work, SIMS data have been normalized by radiochemical and mass spectrometric analysis of adjacent samples.
\end{abstract}

\section{Introduction}

Utilisation of "burnable absorbers" in nuclear light water reactors (LWR's) is a method for implementing near term improvements such as 18 month fuel cycles and maximized average fuel burnup. Among the "burnable poisons", $\mathrm{Gd}_{2} \mathrm{O}_{3}$ is a leading candidate. It has been used in boiling water reactors (BWR's) for some years. When the two isotopes ${ }^{155} \mathrm{Gd}$ and ${ }^{157} \mathrm{Gd}$ with thermal neutron capture cross sections of 61000 and 254000 barn [1] are burnt out, the residual poisoning is negligible. As $\mathrm{Gd}_{2} \mathrm{O}_{3}$ can readily be mixed with $\mathrm{UO}_{2}$, it can be implemented at the most appropriate locations in the fuel assemblies without negative effects on heat transfer or water/fuel ratio for example. Additionally, it does not adversely affect spent fuel storage and reprocessing. Because uncertainties in the bumup calculation of $\mathrm{Gd}$ rods are still too large and since experience on the effect of Gd presence on high burnup behaviour is limited, it has not been possible to fully exploit its possibilities. The GAP programme ${ }^{1}$ is devoted to the acquisition of experimental results required to complement the available data base for pressurized water reactors (PWR's). Determination of burnup values on fuel samples by dissolution, chemical separation and mass spectrometric isotopic dilution analysis is a classical method used in destructive post-irradiation examination. It provides basic values for fuel rod performance and behaviour. To evaluate the radial isotopic distributions of $\mathrm{Gd}$, the same method could be applied to samples produced by microdrilling. This technique is very time consuming and the lateral resolution is limited by the diameter of the drill. An alternative technique for the measurement of local isotopic compositions is Secondary Ion Mass Spectrometry (SIMS). This method is faster and provides greater lateral resolution. In order to quantify the SIMS data, it is necessary to use average isotopic abundance values evaluated by dissolution and mass spectrometry for their normalization.

Alternatively, isotopic calibration standards with a chemical composition comparable to the fuel samples may be used.

\section{Experimental}

In the hotlaboratory of the Paul-Scherrer-Institute (PSI) a modified A-DIDA-SIMS ${ }^{2}$ apparatus has been installed for the analysis of highly radioactive samples [2]. The instrument is equipped with a quadrupole mass analyzer. An HP 9836 desk computer together with an HP 6942 multiprogrammer controls the spectrometer settings and is used for data processing.

For the analysis of polished cross sections of irradiated fuel, an $\mathrm{O}_{2}^{+}$primary ion beam of $12 \mathrm{keV}$ energy was applied. The beam current used was about $50 \mathrm{nA}$ with a spot size of around $10 \mu \mathrm{m}$. Surface scans were performed by moving the specimen across the primary beam in steps of $0.25-0.50 \mathrm{~mm}$ in the $x$ - and $y$-directions, resulting in about $200-800$ point areas analyzed per fuel sample. In order to smooth out inhomogeneities in isotopic composition caused by self-shielding in the gadolinia grains, the primary beam was scanned over an area of about $100 \times$ $100 \mu \mathrm{m}^{2}$.

Evaluation of radial isotopic Gd distributions was effected using $\mathrm{GdO}^{+}$peaks, because the count rates for the oxide ions were about $2-3$ times higher than for the

\footnotetext{
1 "International Experimental Programme on GAdolinia Fuel Evolution in PWR's (GAP)", programme conducted by BELGONUCLEAIRE (BN), Brussels, Belgium, and CENTRE D'ETUDE DE L'ENERGIE NUCLEAIRE/STUDIECENTRUM VOOR KERNENERGIE (CEN/SCK), Brussels, Belgium
}

2 ATOMIKA Technische Physik GmbH, Postfach 450135, D-8000 München 45, FRG 
metallic ions. The interference risk of fission product ions is also thus reduced. Absolute secondary ion count rates can vary considerably, and some of the influencing factors are:

- extraction field variations due to sample movement

- primary beam current variations

- variation of the primary beam incident angle and secondary ion take off angle due to sample cracks and pores

- true concentration variations within and between fuel and gadolinia grains

- and variation of secondary ion yield due to varying properties of the sample matrix.

As a first step in data evaluation, all the raw gadolinium count rates were divided point for point by the count rate for ${ }^{160} \mathrm{Gd}$. With a thermal neutron capture cross section of 0.77 barn, it can be assumed that the original ${ }^{160} \mathrm{Gd}$ content is not significantly changed during fuel irradiation at low burnup. This step eliminates most geometrical and chemical effects.

These normalized count rates were then transformed into local isotopic compositions by comparing the average SIMS values with radiochemically determined isotopic compositions of adjacent samples.

Fuel samples with an initial ${ }^{235} \mathrm{U}$ enrichment of about $3.5 \%$ and $\mathrm{Gd}_{2} \mathrm{O}_{3}$ concentrations of about 3 and $7 \mathrm{wt} \%$ have been analyzed. The burnup values were between 2 and $6 \mathrm{GWd} / \mathrm{tM}$. A photomacrograph of a typical sample is shown in Fig. 1.

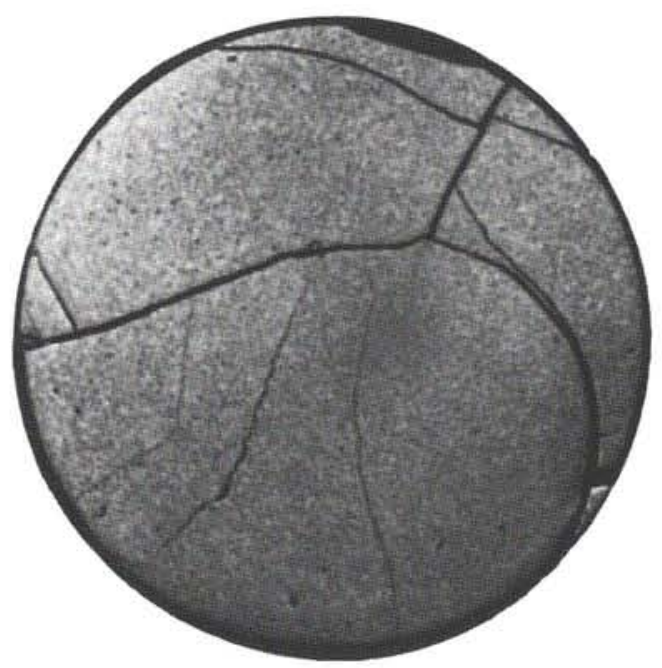

Fig. 1. Photomacrograph of a typical cut and polished fuel cross section.

Fig. 2 shows ${ }^{155} \mathrm{Gd}$ count rates normalized to ${ }^{160} \mathrm{Gd}$ from three measurements of the sample shown in Fig. 1. Datapoints along the same diameter were extracted from surface scans performed with different step widths. Shape and maximum value of all three measurements are similar. The difference between the lowest and highest value in the peak region of the curves, corresponding to values at the pin centre, is about 0.025 or less than $15 \%$ of the approximate mean value of 0.2 . Average values calculated

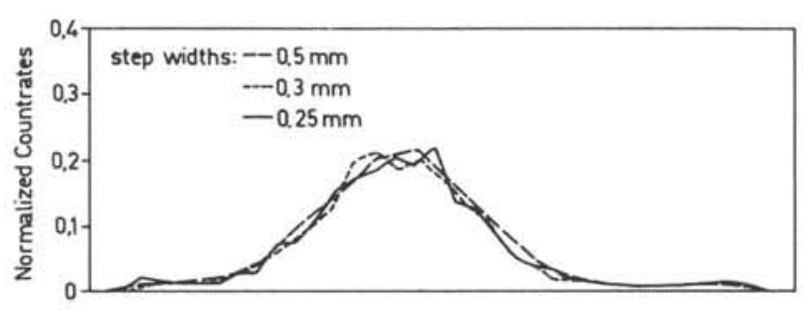

Fig. 2. Comparison of three different scans for radial ${ }^{155} \mathrm{Gd}$ distribution. (Countrates normalized to ${ }^{160} \mathrm{Gd}$ countrates.)

for the whole specimen surface from the same three measurements show ranges of less than $10 \%$ for the Gd isotopes $154,155,156,158$ and $160 .{ }^{157} \mathrm{Gd}$ is burnt out to about $0.1 \%$ of the original content. This illustrates that SIMS measurements are reproducible, even if the sample surface is partly cracked and porous.

\section{Results and discussion}

In Fig. 3 three-dimensional presentations of the radial ${ }^{155} \mathrm{Gd}$ distribution are shown together with the relative axial ${ }^{137} \mathrm{Cs}$ distribution evaluated by gamma-spectrometry [3]. The ${ }^{137} \mathrm{Cs}$ distribution is a measure of the local fuel burnup. The three-dimensional pictures show qualitatively, how the width and height of the ${ }^{155} \mathrm{Gd}$ distribution vary in function of the local fuel burnup.

For quantitative informations, this type of data presentation is not suitable. Quantitative information from the whole sample cross section can be displayed in contour plots. In Figs. 4 and 5 the same data as in Fig. 3 are used to show the ${ }^{155} \mathrm{Gd}$ distribution in the two samples $\mathrm{A}$ and $D$ with the highest and lowest burnup values. This type of data presentation gives information about asymmetrical burnup and the width of single nuclide distribution. If informations on more than one nuclide are to be compared, it is easier to extract a part of the data, e.g. along a diameter, and to plot them in line graphs as in Figs. 6 and 7. These figures show the distribution of the Gd isotopes $155-158$ in samples A and D along the diameters indicated in Figs. 4 and 5. The plots show how the two isotopes ${ }^{155} \mathrm{Gd}$ and ${ }^{157} \mathrm{Gd}$ are converted into ${ }^{156} \mathrm{Gd}$ and ${ }^{158} \mathrm{Gd}$, respectively. The conversion is caused by thermal neutron capture and starts at the periphery of the pin. The lower isotopic contents in the central part of sample D compared to the original natural isotopic abundances of $14.80 \%\left({ }^{155} \mathrm{Gd}\right)$ and $15.65 \%\left({ }^{157} \mathrm{Gd}\right)$ are due to resonance reactions with fast neutrons.

\section{Acknowledgements}

GAP programme management and committee members, especially DIDIER HAAS and PATRICK BLANPAIN of Belgonucleaire and RICHARD W. STRATTON of PSI contributed to the success of this work with their advice and encouragement.

Sample preparation was performed by the PSI hotcell group, in particular ALBERT ERNE. We are obliged to LYALL SMITH of PSI for critical review of the manuscript. 


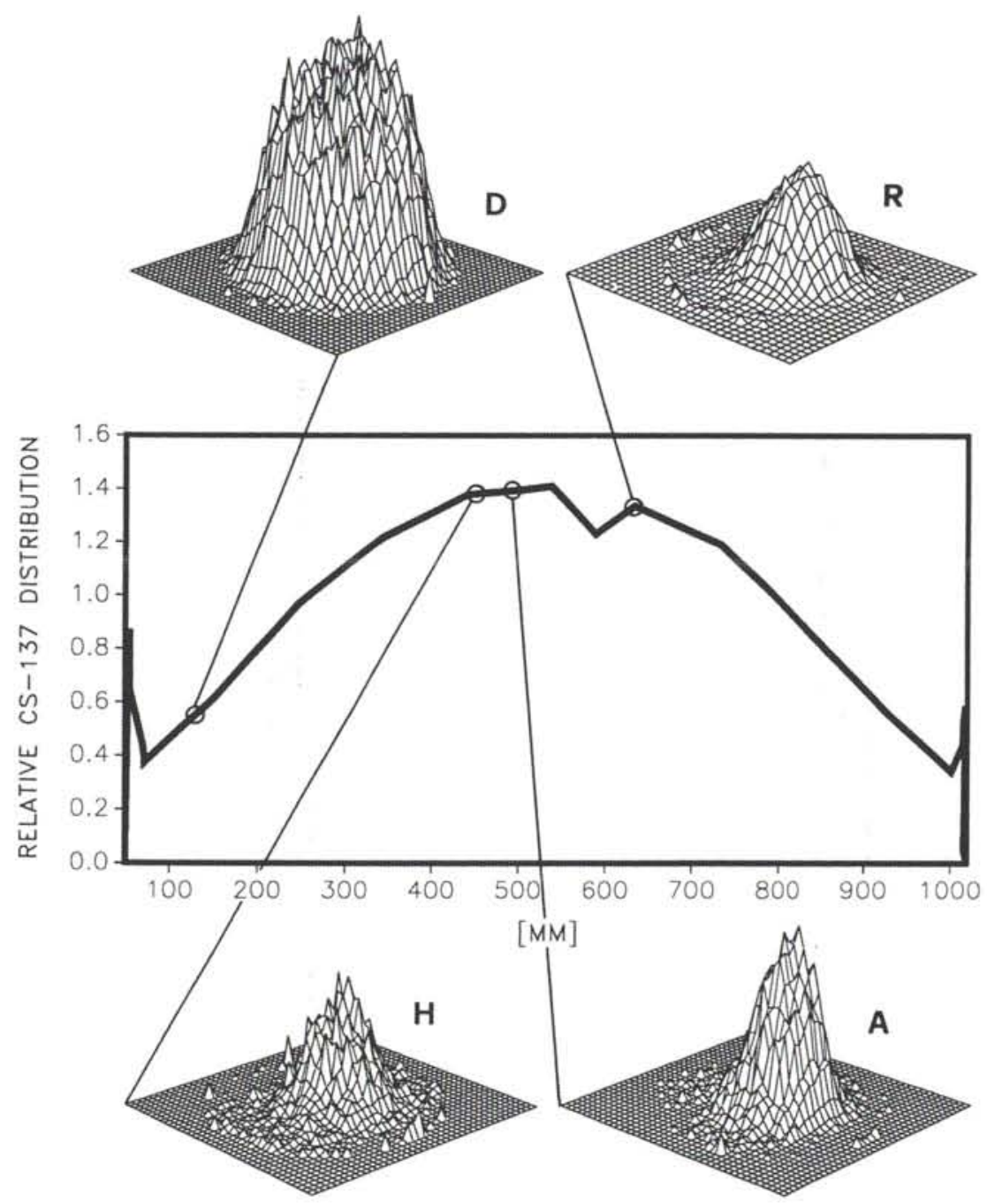

Fig. 3. Axial ${ }^{137} \mathrm{Cs}$ distribution in a fuel pin and radial ${ }^{135} \mathrm{Gd}$ distribution at different burnup levels [3].

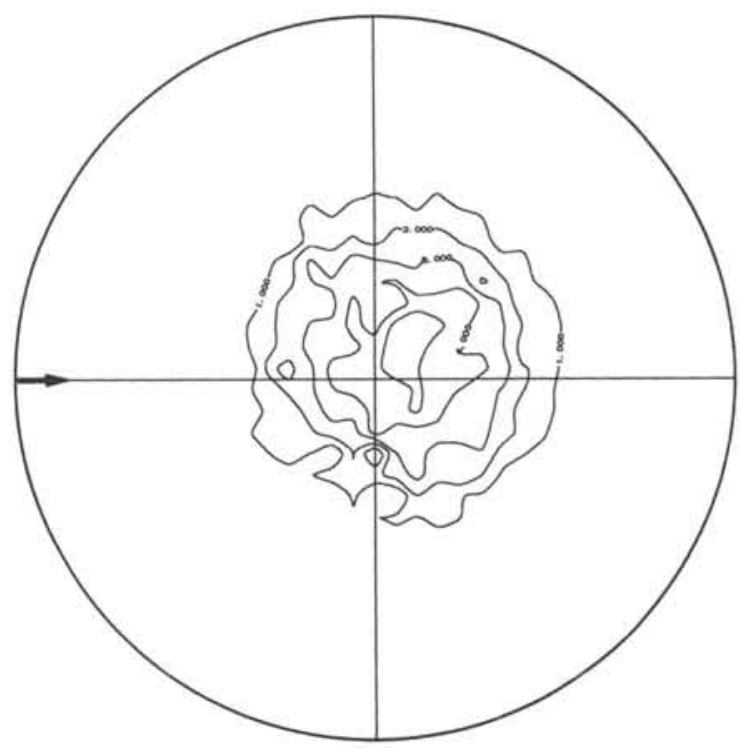

Fig. 4. Contour plot of ${ }^{155} \mathrm{Gd}$ distribution in sample $\mathrm{A}$. One contour interval corresponds to a difference in isotopic abundance of $1 \%$. The arrow indicates the direction of the radial plot in Figure 6.

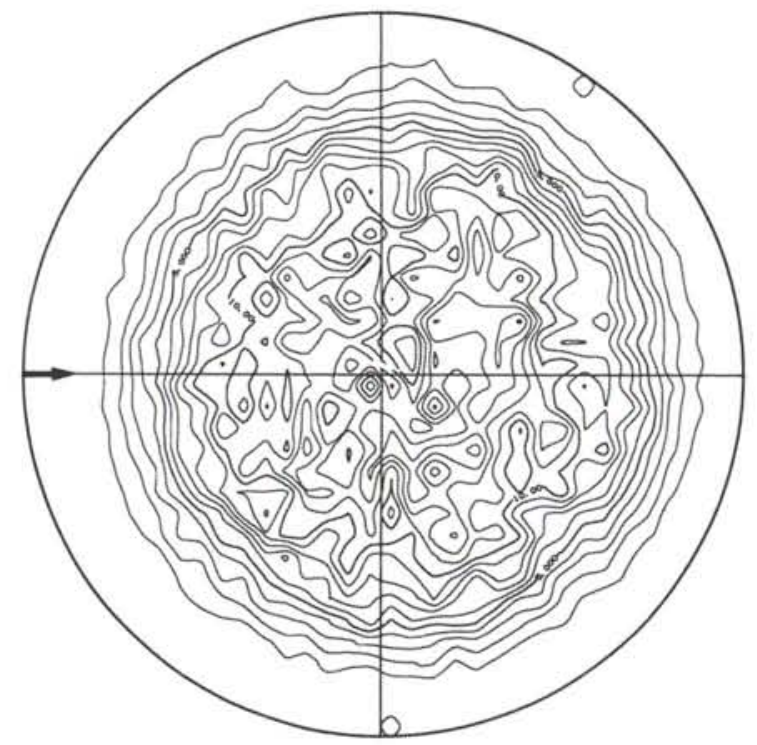

Fig. 5. Contour plot of ${ }^{155} \mathrm{Gd}$ distribution in sample D. One contour interval corresponds to a difference in isotopic abundance of $1 \%$. The arrow indicates the direction of the radial plot in Figure 7 . 


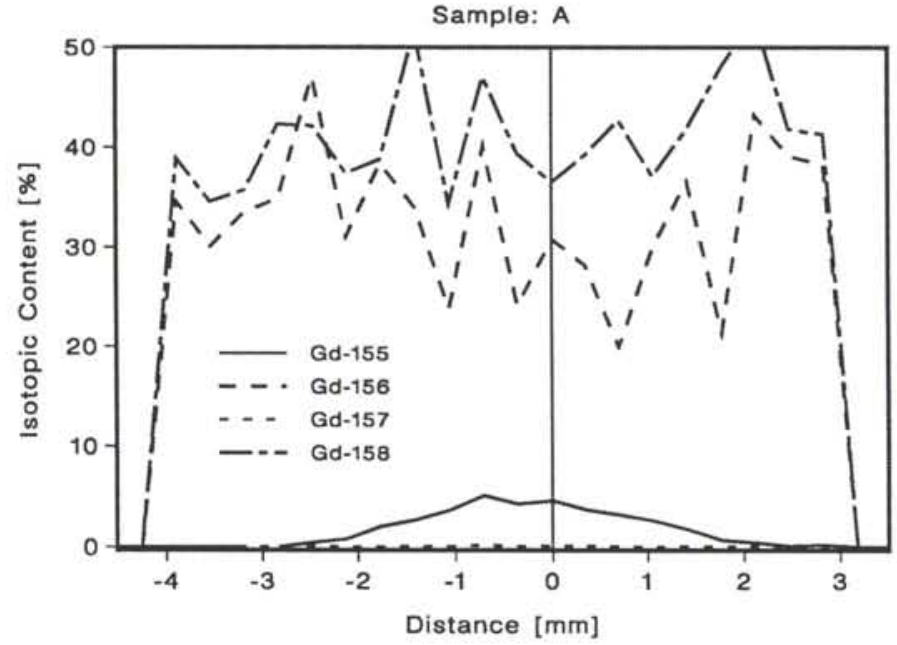

Fig. 6. Radial distribution of Gd isotopes $155-158$ in sample A along the diameter indicated in Figure 4.

\section{References}

1. SeElmanN-Eggebert, W., PFenNig, G., MUENZEL, H., KLEWE-NEBENIUS, H.: Chart of the Nuclides, 5 th ed., Kernforschungszentrum Karlsruhe $\mathrm{GmbH}, 1981$.

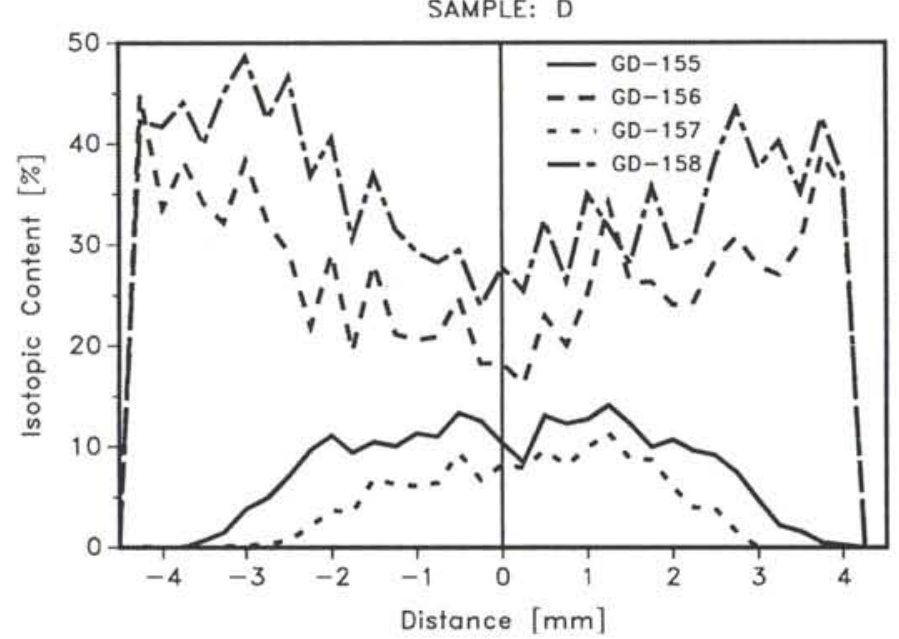

Fig. 7. Radial distribution of Gd isotopes $155-158$ in sample D along the diameter indicated in Figure 5.

2. BART, G., AERNE, E. T., FLUECKIGER, U., SPRUNGER, E.: Modification of a Secondary Ion Mass Spectrometer to allow the examination of highly radioactive specimens. Nucl. Instr. and Meth. 180, 109 (1981).

3. BLANPAIN, P., BOULANGER, D.: Unpublished Work, Belgonucléaire (BN), Brussels, Belgium. 